\title{
Reaching Equal Health in Sri Lanka: A Gender Perspective
}

\author{
Janaki Vidanapathirana ${ }^{a},{ }^{*}$ \\ a National Cancer Control Programme, Ministry of Health Sri Lanka, Elvitigala Mawatha, Colombo 05, Sri Lanka. \\ *Corresponding author Email: kavigaya@yahoo.com \\ DOI: https://doi.org/10.34256/ajir2134
}

Received: 09-08-2021; Revised: 17-09-2021; Accepted: 20-09-2021 Published: 27-09-2021

\begin{abstract}
Gender equity is at the cornerstone of the Universal health coverage (UHC), where no one is to be left behind. This paper highlights the Sustainable Development goal 5 and goal 3 with relevance to the Sri Lankan situation under the topic of "Reaching equal health: a Gender Perspective. The Sri Lankan Gender Gap Index holds the $116^{\text {th }}$ position out of 152 countries. Higher mortalities are observed in males, while higher morbidity is observed in females. Social isolation and poverty in females are common in addition to the diseases at old age. Gender roles and masculine identities have led men to be more vulnerable to risk behaviours and seek access to healthcare services less. The Gender equity is at the cornerstone of the Universal Health Coverage which should be targeted to provide health services for all individuals and communities which they need, without suffering financial hardship by 2030. Sexual and Gender Based Violence (SGBV) is a major determinant of health and females are more vulnerable for that. Unmet need of family planning and abortions are leading causes for maternal mortality. 25,000 abortions occur every year in Sri Lanka. Lesbian, Gay, bisexual, transgender, and queer populations and people with special need are more vulnerable for not getting equal health. Strengthening the health policies and guidelines should be addressed to reduce gender inequalities. Indicators of sex disaggregated data should be included in the routine assessment of all healthcare settings and research agenda should be in place to identify gender inequalities in health research.
\end{abstract}

Keywords: Gender equity, Sri Lanka, Sexual and Gender Based Violence, Healthcare

\section{Introduction}

Sri Lanka records the highest heath indicators and has many good records on human development dimensions compared to many other countries in the region. The Sri Lankan healthcare system provides free of charge healthcare at the point of delivery. This would further complement the system by adopting the Universal Health Care Policy in the country. The Ministry of Health is primarily responsible for the provision of comprehensive healthcare in the public sector. Sri Lanka has a vast network of healthcare institutions and network for both preventive and curative services and it reaches the grass root. The preventive health services are provided mainly through the public health sector and organized through the Medical Offices of Health with a catchment area of $60,000-100,000$ people in the grass root level. They provide a range of services relevant to communicable and non-communicable diseases. The provision of curative healthcare from the public health sector is carried out through a network of hospitals which consist of Teaching Hospitals, Provincial Hospitals, District Hospitals, Base Hospitals, Primary Healthcare Hospitals and Central Dispensaries. In the private sector, there are three main groups of providers: hospitals, clinics and diagnostic services. The public sector model offers free services at all levels of healthcare. $90 \%$ of in-patient care is delivered within the public sector. Out-patient care is delivered more equally between the public and private health sector (Ministry of Health, Nutrition and Indigenous Medicine Sri Lanka, 2019).

The World Health Organization declared polio-free in 2014, elimination of Malaria in 2016, and measles in 2019, Rubella and Congenital Rubella Syndrome in 2020, Mother-to-Child transmission of HIV, Mother to child transmission of Syphilis in 2020 (Perera B.J.C., 2020). This was a remarkable achievement of the country. However, the country faces numerous challenges in the health system and Ministry of Health is working with other 
stakeholders to ensure the provision of efficient, effective, and equitable services to overcome these challenges. It was observed that certain indicators are challenging to improve further. Gender inequity on the other hand, plays a significant role in the achieving of quality health status. Therefore, it is essential to reduce the gender inequality to further improve those health indicators.

The United Nations has adopted sustainable development goals to achieve 17 goals and 169 targets to improve the quality of each person's life, with no one being left behind by 2030 (United Nations, 2021). Each goal is dependent on other goals and they are universal, and integrated. Sri Lanka is working to achieve sustainable development targets through multisectoral partnership of government and non-governmental organizations. Goal 5 addresses the gender equality and goal 3 addresses the good health and wellbeing. Goal $3-$ health is central to all 17 goals and if it is not achieved, the implementation of all other goals will be compromised.

This paper highlights the connection between goal 5 and goal 3 in relevance to the Sri Lankan situation under the topic of "Reaching equal health: a Gender Perspective".

\section{Universal Health Coverage and Gender Gap Index}

The United Nations is targeting the achievement of Universal Health Coverage with the objective of providing health services for all individuals and communities which they need, without suffering financial hardship by 2030 (World Health Organizations, 2021 c). The Gender equity is at the cornerstone of the Universal Health Coverage and emphasizes on the fact that no one is to be left behind.

The Gender Gap Index is calculated based on the data on economy, education, health \& political empowerment. The Sri Lankan Gender Gap Index holds the $116^{\text {th }}$ position out of 152 countries and accounts for $67 \%$, while Iceland and Finland being the highest with $89 \%$ and $86 \%$ respectively (World Economic Forum, 2020). Sri Lanka needs a further $33 \%$ to close this gender gap.

When considering the overall picture, males have a high mortality while female show high morbidity, for which the biological sex difference as well as the gender inequality are two of the main reasons. The Gender inequality leads to negative outcomes, especially for females and is in favour of men in many societies. Since the females have more life expectancy, the social isolation and the poverty among females, leading to economic dependence at later stage is more common.

Gender is one of the social determinants of health. It is embedded in other social determinants like education and poverty which influences health outcomes and access to health services. Although many laws \& policies in the country, promote for better health outcome, there are few restrictive laws like, 365A of the penal code (Democratic Socialist Republic of Sri Lanka, 1995). and vagrants ordinance (Democratic Socialist Republic of Sri Lanka, 1841) leading to reduced access to health services and hinders the provision of services rendered to key population groups. This is further aggravated by negative attitudes of the service providers. When gender inequality exists, the negative health outcomes for women than men would be more.

According to the research on Women's Wellbeing Survey - 2019 in Sri Lanka, almost half of the women had negative attitudes to the unequal power relations between men and women. It further revealed that $47 \%$ women had agreed that "a man should show that he is the boss", 46\% women agreed that "a good wife obeys her husband even if she disagree" and 39\% women agreed that "it is a wife' s obligation to have sex with her husband even if she does not feel like it". These attitudes contribute to unequal power distribution between both sexes and it directly as well as indirectly affects the health and healthcare access including the healthcare services given by healthcare providers

\section{Disability Adjusted Life Years}

Disability Adjusted Life Years (DALYs) is one way of measuring the burden of diseases by summing up the years of life lost due to premature mortality. Disability Adjusted Life Years for 359 diseases revealed that female has more disability than male in the Southeast Asian region (Christopher. JL. Murray et al. 2018). 


\section{Contraceptive as an investment}

Investments in provision of contraceptives yield social and economic returns and reduced maternal and infant mortality. The Demographic Health Survey 2016 revealed that the contraceptive prevalence rate among women aged 15-49 was 65\% in Sri Lanka and was the highest level in the region. But it was only $43 \%$ among the currently married 15-19 age group and was equal to the lowest level in the region. Sri Lanka needs to pay attention to improve the situation of young married women. Family planning not only protects women from unwanted pregnancies and potential life-threatening complications, but it also allows women much greater access to educational and employment opportunities. The unmet need of family planning was $7.5 \%$ in 2016 (Department of Censes \& Statistics, 2016).

Sri Lanka shows the lowest total fertility rate in the region and it was 2.2 in 2016. A Significant number of teenage pregnancies occur each year, which is around the range of $18,000-24,000$ per year. The percentage of teenage pregnancies, ranging from 4.4 to $4.1 \%$ was static during the 2017 to 2019 respectively (Family Health Bureau, 2020).

At the same time, the fertility rate of young women aged 15- 19 who gave birth or were pregnant with their first child was also a static figure, with a 31\% adolescent pregnancy rate in 1975 and 32\% in the year 2016. There is no difference during the last four decades (Department of Censes \& Statistics, 2016). These data indicate that urgent investment is necessary to reduce the \% of teenage pregnancies, because it gives rise to a negative outcome for both mother and the baby. Laws need to balance autonomy and protection. Our country has allowed the minimum age of sexual consent as 16 years by considering the evolution capacity of young people. Minimum age of marriage is 18 years which doesn't allow the child marriages except among Muslims. Laws do not prevent access of SRH services by young people. But, the society has an impression that there is a barrier. Sri Lanka has laws against rape, sexual and domestic violence. But no legal provision against marital rape. This will affect the lives of young married girls who don't have autonomic capacity over their bodies (Neal. S. et. al., 2012).

\section{Abortions}

Every year 250,000 women undergo illegal abortions in Sri Lanka. WHO has recommended that abortions should be done by balancing the medical reasons and the women's rights to protect the autonomy of their bodies. Although Sri Lankan laws allow rights to the highest attainable standard of wellbeing, abortion is only permitted to save the life of a woman. Social barriers to the access of contraceptives for unmarried young people leave a disproportionate impact. The criminalization of abortion may serve to solidify stigma associated with sexual activity among young people.

The evidence shows that legal restrictions to abortions, do not reduce abortion rates. The criminalization causes women to turn to illicit abortions which often result in increased maternal morbidity and mortality (World Health Organization 2021 a). Presently, the next revision of the Sri Lankan abortion law is approved by the cabinet and parliament approval was withheld due to religious barriers.

\section{Maternal mortality ratio}

Gender inequality plays a significant contribution for the maternal mortality ratio. Sri Lanka showed the lowest maternal mortality rate among the Southeast Asian countries and was 29.2 per 100,000 population in 2019. However, Sri Lanka is aiming for a single digit number. Abortion is one of the significant and direct cause which is important to reduce the unmet need of family planning. The maternal suicide also contributed to maternal mortality ratio, in the recent past, and is also relevant to the gender inequality. Very strong evidence shows female primary education, GDP per capita and gender inequality increases the maternal mortality (Family Health Bureau, 2020).

It further evidenced that female representation in national workforce reduce the maternal mortality. At the same time, when work parity increases, both male and female life expectancy increase. Gender inequalities affect the child mortality and Sri Lankan evidence revealed that wasting, stunting and low birth weight among children decrease with increasing mother's education, Demographic and Health Survey 2016. This reflects the female 
empowerment of deduction for health indictors. Further, analysis shows that Sri Lanka's female labour force participation rate remains low, and the female labour force participation was $33.5 \%$ in 2019 , which was below the world average figure of the $51.96 \%$, out of 181 countries (International Organization of Migration, 2016). Women's health and economy are contributing to overall health of the country. It would be further aggravated by the intimate partner violence and is encountered by about 30-35\% of Sri Lankan women (Guruge S, JayasuriyaIllesinghe V, Gunawardena N, Perera J., 2016). Although it is below the Southeast Asian figures, this contributes to women's own health as well as physical mental and social wellbeing of the family and affects the community, society as well as the whole country.

\section{Female Genital Mutilation}

Female Genital Mutilation is an extreme form of discrimination and violation of the human rights, which reflects inequality between the sexes. It causes decreased pleasure, pain during intercourse with reduced orgasm in the long term, apart from the short term complications like bleeding and infection. This practice is carried out in Sri Lanka, among young girls of a specific ethnic group, to a large extent in a silent manner. The Ministry of Health has issued a circular, prohibiting female genital mutilation by medical professionals. A study carried out in one district in 2019 revealed that the prevalence of FGM among 16-49-year-old ever married Muslim women in the Puttlam district was $92.9 \%$ and $91.5 \%$ among their daughters. Further legal changes need to be done to protect young girls (Ishra Nazeer, 2021).

\section{Non-Communicable Diseases}

Non-Communicable Diseases (NCD) account for majority of death among men. It is associated with risk factors like smoking and alcohol with masculine identities. Gender roles of men lead to poor access to health services (Joanna Sara Valson and V. Raman Kutty, 2018). Currently, there are no special service provisions for men separately. It was noted that male participation for NCD screening services are still low due to gender roles and occupational engagement issues.

There seems to be gender bias in diagnosis and treatment of mental health conditions in men and they are less likely to be diagnosed, leading to a suicide rate almost twice as women. Women with mental health conditions on the other hand, face mistreatment, abuse by family members, forced institutionalization and forced sterilizations. Depression is more common among women and is correlated to both women's biology and their stereotypical gender roles (World Health Organizations, 2021 a).

\section{Lesbian, Gay, bisexual, transgender, and queer populations}

Lesbian, Gay, bisexual, transgender, and queer (LGBTQ) populations have a higher risk for substance use, sexually transmitted diseases, bullying, rejection, anxiety, depression, and suicide as compared to others, like in many other countries. This is due to gender inequality \& restrictive laws in the country leading to higher risk of acquiring HIV too. Section 365(a) of the Sri Lankan Penal Code mentions that 'gross indecency' between two persons is criminal offence and punishable with imprisonment. But the Law has not defined what gross indecency is. This is taken as same sexual behaviours by the Law authorities and often leads to barriers for SRH services of Men who have sex with men. The stigma associated with same sexual behaviours creates significant barriers to accessing services and use of condoms especially among young people (World Health Organizations, 2021 b).

There is no specific legal offence in commercial sex work in private. However, many facets of sex work related legal documents namely, the Vagrancy Ordinance, the Brothels Ordinance and house of detention makes young sex workers reluctant to access Sexual \& Reproductive Health services, and to carry condoms to be used when in need. Condoms are categorized as an essential medical item in the essential drug list of the Ministry of Health (Vidanapathirana J, Premadasa P, Disanayake N, Wijegoonewardene N., 2016 a).

It is high time to Repeal the restrictive laws in Sri Lanka. It is namely: 365A of the penal code \& Vagrants Ordinance (Democratic Socialist Republic of Sri Lanka, 1995) \& (Democratic Socialist Republic of Sri Lanka, 1842). There has been good progress over the past fifteen years in the health sector of the country for LGBTQ population. 
Many initiatives have taken place for providing sexual health services in a more organized way with the partnership of NGOs, capacity building of healthcare providers for zero discrimination and stigma, developing strong partnership between government and community groups. At the same time improvement of health for transgender people by issuing of "Gender Recognition Certificate" to Registrar General has been confirmed by the Ministry of Health circular to facilitate obtaining of the birth certificate by changing the biological sex. However, country needs to fulfill further improvements to provide equal health for all, minimizing the gender gap (Vidanapathirana J, Premadasa P, Disanayake N, Wijegoonewardene N., 2016 b) and (Ministry of Health, 2016).

\section{People with special needs}

People with special needs face challenges regardless of their sex and are more common among females. The main problems being gaining of health knowledge, accessing of healthcare services \& health communication (World Health Organizations, 2021 d). These challenges are more among females due to gender inequality. Some women face forceful sterilization, sexual abuse, and gender-based violence. There is no sex disaggregated data among people with special needs. There are no sign language interpreters at hospital setup even in the level of the National Hospital.

\section{Gender and Research}

Women have been under-represented in many clinical trial research in Sri Lanka as much as in other countries worldwide. Sex-disaggregated data is minimal in many research, as well as in research publications. Many clinical trials exclude women for safety reasons and some trails also excluded women if they were on contraceptives, so that drug interactions are minimized (Anita Holdcroft, 2007). This must be considered during the designing phase, aiming to provide evidence for policy and practice.

\section{Conclusions}

Finally, it can be concluded by stating a set of recommendations to minimize the gap of gender index in Sri Lanka. It is recommended to address and implement the activities relevant to all 17 SDG targets in parallel to multi-sectoral partnership. Restrictive laws leading to reduced access to health should be removed and abortion law needs a balance between medical reasons and rights of autonomy of females. Strengthening the health policies and guidelines should be addressed to reduce gender inequalities. Indicators of sex disaggregated data should be included in the routine assessment of all healthcare settings and research agenda should be in place to identify gender inequalities in health research. These recommendations will help to provide equal health for all by minimizing the gender gap in Sri Lanka.

\section{References}

Christopher JL., Murray et. Al. (2018). Global, regional, and national disability-adjusted life-years (DALYs) for 359 diseases and injuries and healthy life expectancy (HALE) for 195 countries and territories, 1990-2017: a systematic analysis for the Global Burden of Disease Study 2017, Lancet, 392 (10159) 1859-1922. https://doi.org/10.1016/s0140-6736(18)32335-3

Democratic Socialist Republic of Sri Lanka., (1842). Vagrants Ordinance: No. 4 of 1841.Colombo, Sri Lanka: Author.

Democratic Socialist Republic of Sri Lanka., (1995) 365 \& 365A in Penal Code. Colombo, Sri Lanka: Author.

Department of Census and Statistics (DCS 2016) and Ministry of Health, Nutrition and Indigenous Medicine 2017. Sri Lanka Demographic and Health Survey. Colombo, Sri Lanka: Authour.

Department of Census and Statistics., (2020). Women's Wellbeing Survey, Sri Lanka - 2019, Department of Census and Statistics, Sri Lanka, 1-220. 
Family Health Bureau., (2021) Unpublished data for Annual Report of Family Health Bureau (2021), Ministry of Health, Sri Lanka. Authour:

Guruge S., Jayasuriya-Illesinghe V., Gunawardena N., Perera J., (2016). Intimate partner violence in Sri Lanka: a scoping review, Ceylon Medical Journal, 60(4) 133-138. http://doi.org/10.4038/cmj.v60i4.8100

Holdcroft A., (2007). Gender bias in research: how does it affect evidence based medicine?. Journal of the Royal Society of Medicine, 100(1), 2-3. https://dx.doi.org/10.1258\%2Fjrsm.100.1.2

International Labour Organization., (2016). Factors affecting women's labour force participation in Sri Lanka, ILO International Labour Organization, 1-124

Ishra Nazeer., (2021). Prevalence and factors associated with gender-based violence among ever married, 16-49year-old Muslim women and feasibility assessment of a community support group for prevention and mitigation of the risk of gender-based violence in the Puttalam District, Post Graduate Institute of Medicine, University of Colombo, Sri Lanka.

Joanna Sara Valson., Raman Kutty V. , (2018). Gender differences in the relationship between built environment and non-communicable diseases: A systematic review. Journal of Public Health Research, 7(1), 43-49. https://doi.org/10.4081/jphr.2018.1239

Ministry of Health, (2019)., Nutrition and Indigenous Medicine Sri Lanka. Essential Health Services Package -2019. Colombo, Sri Lanka: Authour.

Ministry of Health., (2016). General Circular: Issuing of Gender Recognition Certificate for Transgender Community, 2016 01-34/2016. Colombo, Sri Lanka:Aorthour:

Neal S., Matthews Z., Frost M., Fogstad H., Camacho A.V., Laski L., (2012). Childbearing in adolescents aged 12-15 years in low resource countries: a neglected issue. New estimates from demographic and household surveys in 42 countries. Acta Obstetricia et Gynecologica Scandinavica, 91(9), 1114-1118. https://doi.org/10.1111/j.1600-0412.2012.01467.x

Perera B.J.C., (2020). Elimination of several infectious diseases from Sri Lanka: A tribute to the parents of our children and to our immunisation programme. Sri Lanka Journal of Child Health, 49(4), 317-319. http://doi.org/10.4038/sljch.v49i4.9260

United Nations, (2021). The 17 goals, [Internet]. Available from: https://sdgs.un.org/goals

Vidanapathirana J., Premadasa P., Disanayake N., Wijegoonewardene N., (2016 a). No one left behind understanding key populations: achieving triple zeros by 2030. National STD/AIDS Control Programme \& United Nations Population Fund, Colombo, Sri Lanka.

Vidanapathirana J., Premadasa P., Disanayake N., Wijegoonewardene N., Mallikarachchi D., (2016 b). Let us Know about HIV and AIDS : Achieving Triple Zeros: Handbook on HIV \& AIDS for Primary Health Care Workers, National STD/AIDS Control Programme, United Nations Population Fund, Colombo, Sri Lanka.

World Economic Forum., (2020). Global Gender Gap Report 2020, World Economic Forum. http://www3.weforum.org/docs/WEF GGGR 2020.pdf

World Health Organization., (2008). Fact Sheet on Female Genital Utilization.World Health Organization, Geneva

World Health Organizations, (2021 d). World Report on Disability.2011 World Health Organizations. https://www.who.int/disabilities/world report/2011/report.pdf

World Health Organizations., (2021 a). Abortion. World Health Organizations. https://www.who.int/healthtopics/abortion\#tab=tab 1

World Health Organizations., (2021 b). Gender and Mental Health. 22. World

Health

Organizations.https://www.euro.who.int/en/health-topics/health determinants/gender/activities/genderand-non-communicable-diseases/gender-and-mental-health 
World Health Organizations., (2021 c). Universal health coverage, 23. World https://www.who.int/health-topics/universal-health-coverage\#tab=tab 1

Funding: No funding was received for conducting this study.

Conflict of Interest: The Author has no conflicts of interest to declare that they are relevant to the content of this article.

Data sharing statement: No additional data are available

Does this article screened for similarity: YES

\section{About The License}

(C) The author 2021. The text of this article is open access and licensed under a Creative Commons Attribution 4.0 International License

\section{Cite this Article}

Janaki Vidanapathirana, Reaching Equal Health in Sri Lanka: a Gender Perspective, Asian Journal of Interdisciplinary Research, 4(3) (2021) 37-43. https://doi.org/10.34256/ajir2134 